\title{
Mechanical Properties of Microsteel Fiber Reinforced Concrete and Its Gradient Design in the Partially Reinforced RC Beam
}

\author{
Xiaobing He, ${ }^{1,2}$ Yakun Fang, ${ }^{1,2}$ Qi Luo $\mathbb{D}^{1,2}$ Yong Cao, ${ }^{3}$ Han $\mathrm{Lu}^{4}$ and Runping $\mathrm{Ma}^{5}$ \\ ${ }^{1}$ State Key Laboratory of Mountain Bridge and Tunnel Engineering, Chongqing Jiaotong University, Chongqing 400074, China \\ ${ }^{2}$ School of Civil Engineering, Chongqing Jiaotong University, Chongqing 400074, China \\ ${ }^{3}$ Hunan Branch of Chongqing Luwei Civil Engineering Design Co., Ltd.,, Chongqing 410000, Hunan, China \\ ${ }^{4}$ Chongqing Communications Planning Survey \& Design Institute, Chongqing 401121, China \\ ${ }^{5}$ Inner Mongolia Transportation Design \& Research Institute Co. Ltd.,, Huhhot 010010, China \\ Correspondence should be addressed to Qi Luo; qiluo@cqjtu.edu.cn
}

Received 7 November 2020; Revised 23 November 2020; Accepted 4 December 2020; Published 14 December 2020

Academic Editor: Zhigang Zhang

Copyright (๑) 2020 Xiaobing He et al. This is an open access article distributed under the Creative Commons Attribution License, which permits unrestricted use, distribution, and reproduction in any medium, provided the original work is properly cited.

\begin{abstract}
Effects of two kinds of microsteel fibers were employed in reinforced concrete (RC) with different fiber volumes fraction. The RC beam was partially reinforced by microsteel fiber reinforced concrete (MSFRC) based on the idea of gradient design. Flexural performances were specially investigated. Results show that microsteel fiber highly strengthened and toughened the concrete matrix. With the same fiber volume content, the concrete reinforced by Type I fiber was generally better in strength compared with that of Type II, while the bending toughness was substantially improved. The bending strength of the concrete reinforced by microsteel fiber in partial section of tensile region was comparable to that in whole section. Based on the traditional strength theory, the critical MSFRC layer depth of in the partially reinforced RC beam was about 0.3 times of the beam depth, which possessed the same crack resistance ability with the beam composed of MSFRC in the whole section. Compared with that of the reference beam, the cracking load of the partially reinforced beam was enhanced by $119 \%$, and the ratio of the cracking moment to ultimate moment improved by $91 \%$. Moreover, the width and height of the cracks in the partially reinforced beam developed much slower than those in the reference beam, and the steady state in which all cracks emerged appeared later; meanwhile, the crack spacing in the pure bending region was smaller, and the number of cracks in the bending-shear region was less, which means that the partially reinforced beam is of excellent properties to resist cracking and bending. Finally, the calculation formula of the bearing capacity of the partially reinforced beam was proposed, which was in good agreement with experimental results.
\end{abstract}

\section{Introduction}

Mixing of randomly distributed steel fibers into fresh concrete can prevent initiation and propagation of cracks in hardened concrete and thus improve strength and toughness of the material. Taking a central Mode I crack of length $2 \boldsymbol{a}$ in an infinitely wide concrete plate subjected to the far-field uniform normal stress $\sigma$ as example (Figure 1), fibers in concrete can be assumed to perpendicular to the crack line (the effects of oblique fibers with crack can be also decomposed into effects of perpendicular and horizontal to crack line) and the separation interfaces between fibers and concrete to be very small; thus, the effect of a fiber can be equivalent to a concentrated force $\boldsymbol{P}$ acting on the crack surface (Figure 2). When the crack spans $\boldsymbol{n}$ fibers, the stress intensity factor $K$ at the crack tip is as follows:

$$
K=K_{I}^{c}-K_{I}^{f}=\sigma \sqrt{\pi a}-\sum_{i=1}^{n} \frac{P_{i}}{\sqrt{\pi a}} \sqrt{\frac{2 a-b_{i}}{b_{i}}},
$$

where $K_{I}^{c}$ is the stress intensity factor of the concrete matrix under $\boldsymbol{\sigma} ; K_{I}^{f}$ is the stress intensity factor generated by fibers, $P_{i}$ is the concentrated force generated by the fiber $i, b_{i}$ is the distance from the fiber $\boldsymbol{i}$ to the crack tip, and $\boldsymbol{a}$ is the length of half crack.

According to equation (1), when $b_{i} \longrightarrow 0$, that is, the crack tip is just approaching the fiber $b_{i}$ infinitely, $K_{I}^{f} \longrightarrow \infty$, which means fibers will generate huge reverse 


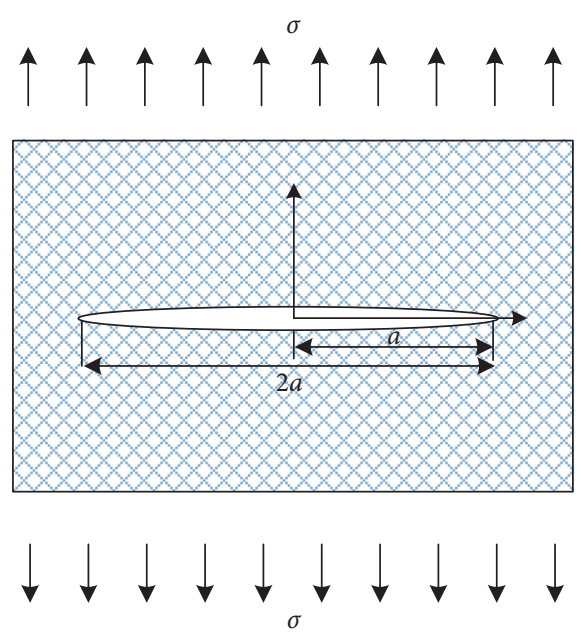

Figure 1: A central Mode I crack of length $2 a$ in an infinitely wide concrete plate.
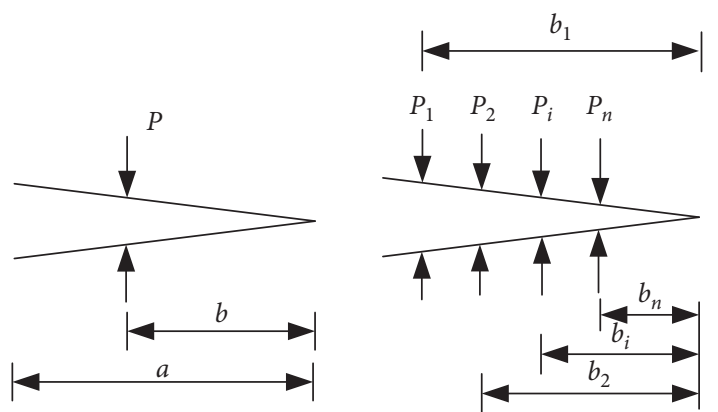

FIgURE 2: Equalizing fibers effect as a series of concentration force $P$ on the crack surface.

stress intensity factor to prevent crack propagation; all other things being equal, the more the number of fibers per unit volume concrete, the more remarkable crack-retarding effect. If the fiber diameter is reduced by half, while the length remains the same; then the original one fiber is equivalent to the current four microfibers in volume; the bonding area between fiber and concrete matrix is doubled consequently, the fiber pull-out force is double that of the original in the case of the same bonding strength and detaching zone between concrete and fiber; under the circumstance of the same fiber pull-out force, the bonding detachment zone would be reduced, and the closure force provided by fibers, namely, the concentration force $\boldsymbol{P}$, is closer to the crack face; thus, the crack-retarding effect is better. This shows that the crack-retarding and toughening effect of microsteel fiber will be more promising.

Compared with conventional concrete, steel fibers reinforced concrete (SFRC) has excellent mechanical properties and durability [1]. However, in a large number of related studies on SFRC, the typical steel fiber employed in concrete matrix is generally 0.5 to $0.8 \mathrm{~mm}$ in diameter or equivalent diameter, 30 to $60 \mathrm{~mm}$ in length, and $0.5 \%$ to $3.0 \%$ in the fiber volume fraction [2-4]. In recent years, microsteel fibers have been used in high performance concrete [5-9], usually with the diameter about $0.2 \mathrm{~mm}$, which have shown that [10-12] the crack-retarding and toughening effect of the Type I microsteel fiber (usually smooth cold-drawn wire with about $0.2 \mathrm{~mm}$ in diameter) in SFRC are better than those of the larger diameter steel fiber, while the effect of the Type II micro steel fiber (deformed cut sheet) remains to be studied. Therefore, the first step, two kinds of microsteel fibers (Type I, the smooth cold-drawn wire, and Type II, deformed cut sheet) with a diameter or equivalent diameter of $0.2 \mathrm{~mm}$ and length of $13 \mathrm{~mm}$ are employed to study their crack-retarding and toughening effects, which are shown in Figures 3 and 4.

Due to good properties of SFRC, in the 1970s, Swamy used SFRC to enhance the flexural behavior of RC beams and found that the strengthening effect of SFRC, which is in the total section of the beam or tension zone or as a tensile skin, is almost identical. In the 1980s, Sri Ravindrarajah and AlNoori [13] studied the effect of steel fiber distribution on the ultimate strength of concrete beams and revealed that the fiber in the compression zone does not significantly improve the beam strength, while partially reinforced beams are composed of fibers in the bottom layer even about $25 \%$ more than that for the fully reinforced beams [14]. In 1998, Yi and Shen proposed the concept of partially high percentage fiber reinforced concrete (PHPFRC), and full load-deflection curves of flexural PHPFRC specimens indicated that the crack resistance, bearing capacity, and stiffness were enhanced significantly $[15,16]$. In 2001, based on experimental tests of RC beam partially with SFRC, Zhao et al. got the anticracking capacity formulation of the normal section of the beam [17]. In 2002, researches on cement-based functionally graded material showed that fibers should be distributed according to the stress field characteristics of materials [18]. Based on the research of engineered cementitious composites (ECC), Qin et al. put the concept of ultrahigh toughness cementitious composites (UHTCC) obtaining functionally graded composite beam by using UHTCC to replace part of the concrete, which surrounds the main longitudinal reinforcement, and studied its bending properties $[19,20]$. ECC is a kind of highly ductile fiber reinforced concrete; it shows a special strain-hardening behavior under tensile loadings; meanwhile, along with developing multiple microcracks on specimens, as a result, its tensile strain capacity is several hundred times of convention concrete [21-23]. Additionally, such the microcracks can be self-healed under certain exposure conditions [24-26]. Due to the above unique characteristics, ECC is expected to improve the structural performance of infrastructures [27, 28]. In recent years, partially reinforced beams with fiber also have been involved in concrete composite structures composed of ECC and FRP bars $[29,30]$. The strength and durability of conventional concrete are dominated by the low tensile strength at the interfacial transition zone between mortar matrix and aggregates, where cracks tend to appear and propagate. For steel fiber reinforced concrete, the high tensile strength and bridging capability between fibers and matrix can resist the crack initiation and propagation, leading to high load-carrying capability, ductility, and durability [31,32]. According to the above studies, partially reinforced beam with fibers 


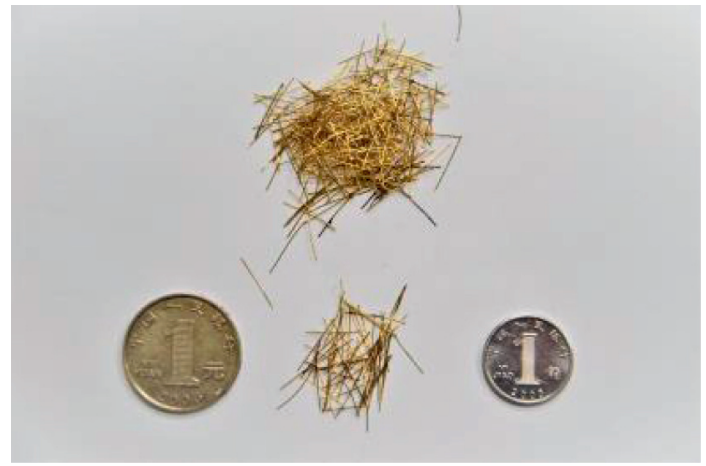

FIgURE 3: Type I (smooth cold-drawn wire) microsteel fiber.

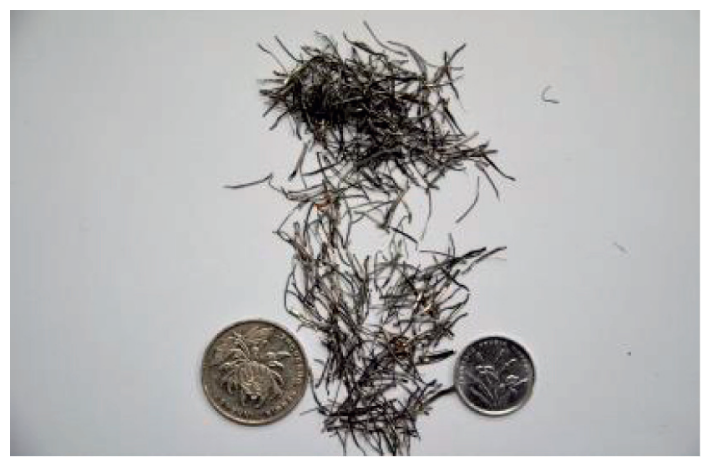

Figure 4: Type II (deformed cut sheet) microsteel fiber.

can fully utilize the crack-retarding and toughening effects of fiber reinforced concrete and is characterized with good cost-effectiveness. But, due to design theory, construction technology, and some other factors, a large number of research and application of SFRC members usually adopt fullsection design, namely, steel fibers usually used in total section.

Therefore, based on the MSFRC research and the characteristics of the stress field of the beam structure, the critical thickness of MSFRC layer in RC beam partially reinforced by MSFRC was obtained based on the traditional strength theory, and the bending capacity of the partially reinforced beam was studied further.

\section{Critical Depth of MSFRC Layer of the Partially Reinforced Beam Based on Strength Theory}

According to the characteristics of the stress field of the beam structure due to bending and the idea of gradient design, the partially reinforced concrete beam was obtained by using MSFRC to replace part of normal concrete in the bottom layer of tension zone. For simplicity, taking a rectangular section as an example, it is assumed that the strain distribution of the normal section of the partially reinforced beam conforms to the plane section in the critical state of cracking, and the stress and strain distribution of the beam are shown in Figure 5. When the MSFRC layer $h_{f}$ is relatively thin, the strain $\varepsilon_{\mathrm{tc}}$ of the upper concrete of the interface between the normal concrete layer and the MSFRC layer reaches the cracking strain earlier. When the MSFRC layer $h_{f}$ is relatively thick, the

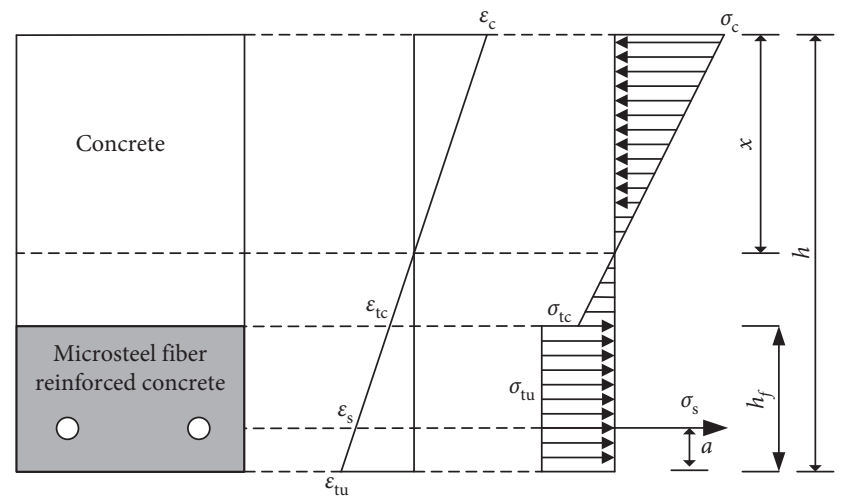

FIGURE 5: Cracking moment calculation diagram of normal section.

strain $\varepsilon_{t u}$ of the lower MSFRC reaches the cracking strain earlier. When $h_{f}$ reaches the critical depth, $\varepsilon_{\mathrm{tc}}$ and $\varepsilon_{\mathrm{tu}}$ simultaneously reach the cracking strain, respectively. In the critical state, taking $\varepsilon_{\mathrm{tc}}$ and $\varepsilon_{\mathrm{tu}}$ as known quantities into equation (2), the critical depth of the MSFRC layer $h_{\mathrm{fcr}}$ can be obtained. If $h_{f}<h_{\mathrm{fcr}}$, the strain of the normal concrete at cracking $\varepsilon_{\mathrm{tc}}$ is known, while $\varepsilon_{\mathrm{tu}}$ is variable; then the relationship between the depth of the MSFRC layer $h_{f}$ and the cracking moment of the beam $M_{\mathrm{cr}}$ can be obtained by taking the cracking strain $\varepsilon_{\mathrm{tc}}$ into (2). If $h_{f}>h_{\mathrm{fcr}}$, the relationship between $h_{f}$ and $M_{\mathrm{cr}}$ also can be obtained by taking $\varepsilon_{t u}$ as a known quantity into the following equation:

Here, in the critical state of cracking, $x$ is the compression zone depth of the composite beam; $h, b, h_{f}$, and $a$ 
are the section depth, the section width, the MSFRC layer depth, and the concrete cover depth of the beam; $\varepsilon_{\text {tu }}$ and $\varepsilon_{s}$ are the tensile strain of MSFRC and the reinforcement, while $\sigma_{\mathrm{tu}}$ and $\sigma_{s}$ are the corresponding stress; $\varepsilon_{t c}$ and $\varepsilon_{c}$ are, respectively, the tensile and compressive strain of the normal concrete, while $\sigma_{\mathrm{tc}}$ and $\sigma_{c}$ are the corresponding stress; $M_{\mathrm{cr}}$ represents the cracking moment of the partially reinforced beam due to bending.

Theoretically, the cracking capacity of the partially reinforced beam with MSFRC increases with the depth of the
MSFRC layer until the critical depth and then tends to stabilize, which mainly depends on mechanical properties of MSFRC and the normal concrete. The relationship trend between the cracking moment $M_{\mathrm{cr}}$ and the ratio of the MSFRC depth to the beam depth hf/h could be obtained as shown in Figure 6. In the critical state of $h_{f}$, the MSFRC layer and the normal concrete layer simultaneously crack and the two materials are utilized most efficiently. Therefore, based on the results of MSFRC, the partially reinforced RC beam with the MSFRC was designed to study its flexural behavior further.

$$
\left\{\begin{array}{l}
\frac{\varepsilon_{c}}{x}=\frac{\varepsilon_{t c}}{h-h_{f}-x}=\frac{\varepsilon_{t u}}{h-x}=\frac{\varepsilon_{s}}{h-x-a} \\
\sigma_{c}=f\left(\varepsilon_{c}\right) ; \sigma_{t c}=f\left(\varepsilon_{t c}\right) ; \sigma_{t u}=f\left(\varepsilon_{t u}\right) ; \sigma_{s}=f\left(\varepsilon_{s}\right) \\
\frac{1}{2} \sigma_{c} x b=\frac{1}{2} \sigma_{t c}\left(h-h_{f}-x\right) b+\sigma_{t u} h_{f} b+\sigma_{s} A_{s} \\
M_{c r}=\frac{1}{2} \sigma_{t c} b\left(h-h_{f}-x\right)\left[\frac{2}{3}\left(h-h_{f}-x\right)+\frac{2}{3} x\right]+\frac{1}{3} \sigma_{t u} h b\left(h-\frac{h_{f}}{2}-\frac{x}{3}\right)+\sigma_{s} A_{s}\left(h-a-\frac{x}{3}\right)
\end{array}\right.
$$

\section{Materials and Test Results}

3.1. Raw Materials. Ordinary Portland cement denoted as Grade P.O. 42.5 was used in this study, and its main properties are given in Table 1. Fly-ash met the requirements of Grade I of the Chinese standard GB1596-2005, and its main properties are shown in Table 2. The size range of continuously graded coarse aggregate (limestone gravel) used was $5-20 \mathrm{~mm}$, and the fineness modulus of fine aggregate (medium-coarse sand) was 2.8; the properties of aggregates are shown in Table 3 . The superplasticizer used was a polycarboxylic water-reducer with water reducing efficiency of $26.6 \%$. Two kinds of microsteel fibers, with the same aspect-ratio of 65 and different volume fraction, were used. Table 4 gives the main properties of microsteel fibers.

3.2. Mixture Proportions. The proportions of MSFRC are summarized in Table 5, where the water-to-binder ratio was maintained unchanged at 0.38 , and the replacement ratio of cement with fly ash in mass at 0.30 . For RC, the reference mixture, the slump flow reaches up to $600 \mathrm{~mm}$. In Table 5, NC stands for concrete without fibers, SFRC-P stands for a series of MSFRC with Type I microsteel fiber, and SFRC-J means with Type II.

3.3. Test Method. According to Chinese standard test method for fiber reinforced concrete CECS13:2009 and standard for test method of mechanical properties on ordinary concrete $\mathbf{G B} / \mathbf{T} \mathbf{5 0 0 8 1 - 2 0 0 2}$, totally 108 specimens were made and tested, which were involved with tests of strength, elastic modulus, and flexural toughness.
Displacement control mode was firstly adopted as the loading method to test $28 \mathrm{~d}$ compressive strengths of MSFRC cube of $100 \mathrm{~mm}$ size and prism of $400 \mathrm{~mm} \times 100 \mathrm{~mm} \times 100 \mathrm{~mm}$ size. Load was unloaded till the load dropped to $90 \%$ of the ultimate load, then the compressive strength of concrete cube $\left(f_{\mathrm{cc}}\right)$ and the compressive strength of concrete prism $\left(f_{\mathrm{cp}}\right)$ were calculated according to the ultimate load. After unloading, force control mode was used to test residual compressive strength of the tested specimens till they failed completely; then we can get the residual compressive strength of concrete cube $\left(f_{c c}^{\prime}\right)$ and the residual compressive strength of prism $\left(f_{\mathrm{cp}}^{\prime}\right)$. Prism specimens with size $300 \mathrm{~mm} \times 100 \mathrm{~mm} \times 100 \mathrm{~mm}$ are employed to test modulus of elasticity of MSFRC under compression $\left(E_{c}\right)$.

As for the test of bending strength and modulus, specimens with MSFRC in total section shown in Figure 7 are firstly designed to test their $28 \mathrm{~d}$ bending strengths $\left(f_{\mathrm{ct}}\right)$; meanwhile, the flexural elastic modulus $\left(E_{t}\right)$ of MSFRC in total section was computed according to the relationship of stress to strain of the bending specimen. The strain gauges were placed on the bottom of the pure bending zone of specimens shown in Figure 8. When loading, values of load and strain are acquired synchronously; then $E_{t}$ is calculated by linear regression treatment of the load-strain relationship curve before cracking, which is determined according to observed mutant strain or a visible crack.

When the properties of MSFRC in total section were obtained, the critical depth of MSFRC layer of the partially reinforced specimen without the reinforcement rebar was estimated to be about one-third of the specimen section depth according to (2), varied with the fiber content, where $\varepsilon_{\mathrm{tu}}, \sigma_{\mathrm{tu}}, \varepsilon_{\mathrm{tc}}$, and $\sigma_{\mathrm{tc}}$ were approximately evaluated according 


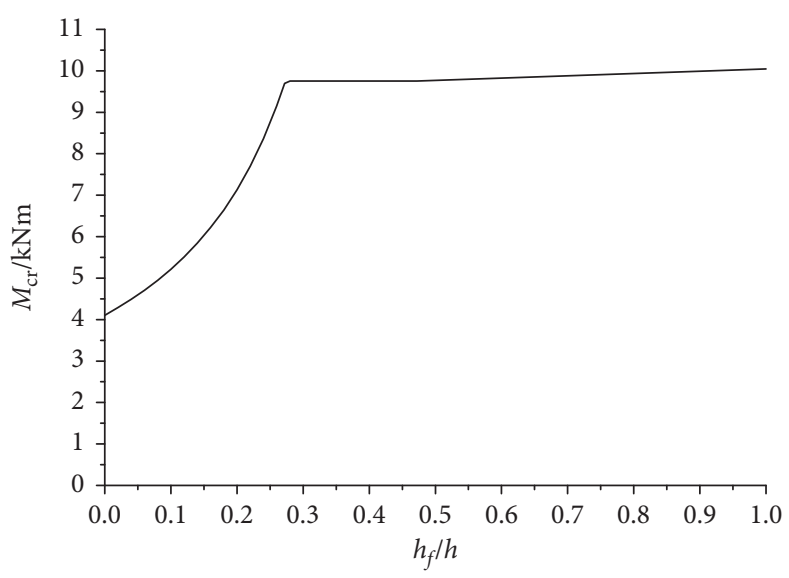

FIgure 6: Relationship trend between Mcr and hf/h.

TABle 1: Properties of Portland cement.

\begin{tabular}{|c|c|c|c|c|c|c|c|c|}
\hline \multirow[t]{2}{*}{ Apparent density $\left(\mathrm{kg} \cdot \mathrm{m}^{-3}\right)$} & \multirow[t]{2}{*}{ Sieve residue under $80 \mu \mathrm{m}(\%)$} & \multirow[t]{2}{*}{ Water required for normal consistency (\%) } & \multicolumn{2}{|c|}{$\begin{array}{l}\text { Setting time } \\
\quad(\mathrm{min})\end{array}$} & \multicolumn{2}{|c|}{$\begin{array}{l}\text { Compressive } \\
\text { strength } \\
(\mathrm{MPa})\end{array}$} & \multicolumn{2}{|c|}{$\begin{array}{c}\text { Flexural } \\
\text { strength } \\
(\mathrm{MPa})\end{array}$} \\
\hline & & & Initial & Final & $3 \mathrm{~d}$ & $28 \mathrm{~d}$ & $3 \mathrm{~d}$ & $28 \mathrm{~d}$ \\
\hline 3100 & 0.0 & 27.6 & 145 & 225 & 30.0 & 50.0 & 5.9 & 9.6 \\
\hline
\end{tabular}

Table 2: Properties of fly ash.

\begin{tabular}{lccccc}
\hline $\begin{array}{l}\text { Apparent density } \\
\left(\mathrm{kg} \cdot \mathrm{m}^{-3}\right)\end{array}$ & $\begin{array}{c}\text { Sieve residue under } 45 \mu \mathrm{m} \\
(\%)\end{array}$ & $\begin{array}{c}\text { Specific surface area } \\
\left(\mathrm{m}^{2} \cdot \mathrm{kg}^{-1}\right)\end{array}$ & $\begin{array}{c}\text { Water demand } \\
(\%)\end{array}$ & $\begin{array}{c}\text { Loss on ignition } \\
(\%)\end{array}$ & $\begin{array}{c}\text { Water content } \\
(\%)\end{array}$ \\
\hline 2300 & 4.4 & 460 & 92 & 1.9 & 0.3 \\
\hline
\end{tabular}

TABle 3: Properties of aggregates.

\begin{tabular}{lcccc}
\hline Type & Apparent density $\left(\mathrm{kg} \cdot \mathrm{m}^{-3}\right)$ & Crushing value $(\%)$ & Flat-elongated particle content $(\%)$ & Clay content $(\%)$ \\
\hline Coarse aggregate & 2700 & 12.9 & 13.4 & 1.7 \\
Fine aggregate & 2680 & - & - & 1.67 \\
\hline
\end{tabular}

Table 4: . Properties of microsteel fibers.

\begin{tabular}{|c|c|c|c|c|c|}
\hline Type & Diameter $(\mathrm{mm})$ & Aspect ratio & Density $\left(\mathrm{kg} \cdot \mathrm{m}^{-3}\right)$ & Tensile strength $(\mathrm{MPa})$ & Elasticity modulus (GPa) \\
\hline $\begin{array}{l}\text { Type I, smooth cold-drawn wire } \\
\text { Type II, deformed cut sheet }\end{array}$ & 0.2 & 65 & 7800 & $\begin{array}{c}2850 \\
680\end{array}$ & $\begin{array}{l}240 \\
210\end{array}$ \\
\hline
\end{tabular}

TABLE 5: Mix proportions.

\begin{tabular}{|c|c|c|c|c|c|c|}
\hline Mix no. & $\begin{array}{l}\text { Cement } \\
\left(\mathrm{kgm}^{-3}\right)\end{array}$ & $\begin{array}{l}\text { Fly ash } \\
\left(\mathrm{kgm}^{-3}\right)\end{array}$ & $\begin{array}{c}\text { Coarse aggregate } \\
\left(\mathrm{kgm}^{-3}\right)\end{array}$ & $\begin{array}{c}\text { Fine aggregate } \\
\left(\mathrm{kgm}^{-3}\right)\end{array}$ & $\begin{array}{c}\text { Superplasticizer } \\
\left(\mathrm{kgm}^{-3}\right)\end{array}$ & $\begin{array}{c}\text { Fiber volume fraction } \\
(\%)\end{array}$ \\
\hline $\mathrm{NC}$ & & & 862.6 & 734.5 & & 0 \\
\hline SFRC-P-1.5 & & & 840.5 & 716.0 & & 1.5 \\
\hline SFRC-P-3.0 & 386.8 & 165.8 & 818.5 & 697.4 & 4.6 & 3.0 \\
\hline SFRC-J-1.5 & & & 840.5 & 716.0 & & 1.5 \\
\hline SFRC-J-3.0 & & & 818.5 & 697.4 & & 3.0 \\
\hline
\end{tabular}

to the bending test, $\sigma_{c}$ and $\varepsilon_{c}$ took design standard values of corresponding strength level concrete of Chinese code for design of concrete structures $\boldsymbol{G B}$ 50010-2010. Specimens with MSFRC in partial section are formed by the two-stage casting method. Firstly, the vibrated MSFRC in the tension zone is casted; then, the upper vibration-free ordinary concrete is casted. The time interval between the two castings is controlled within 20 minutes. 


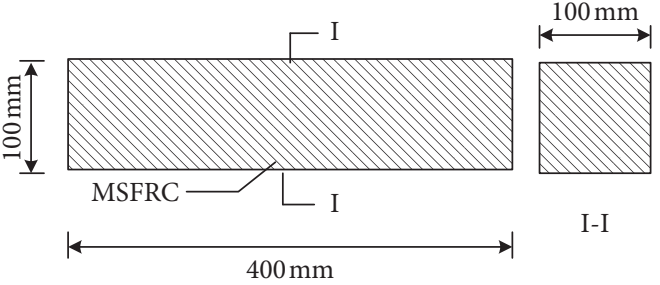

MSFRC in total section

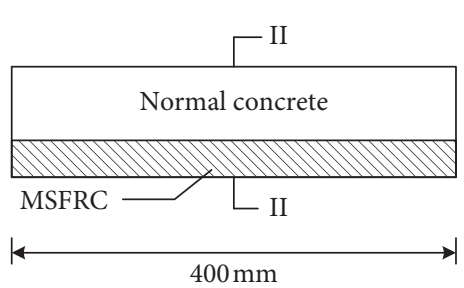

MSFRC in partial section

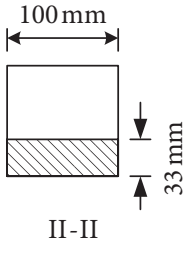

Figure 7: Flexural specimens.

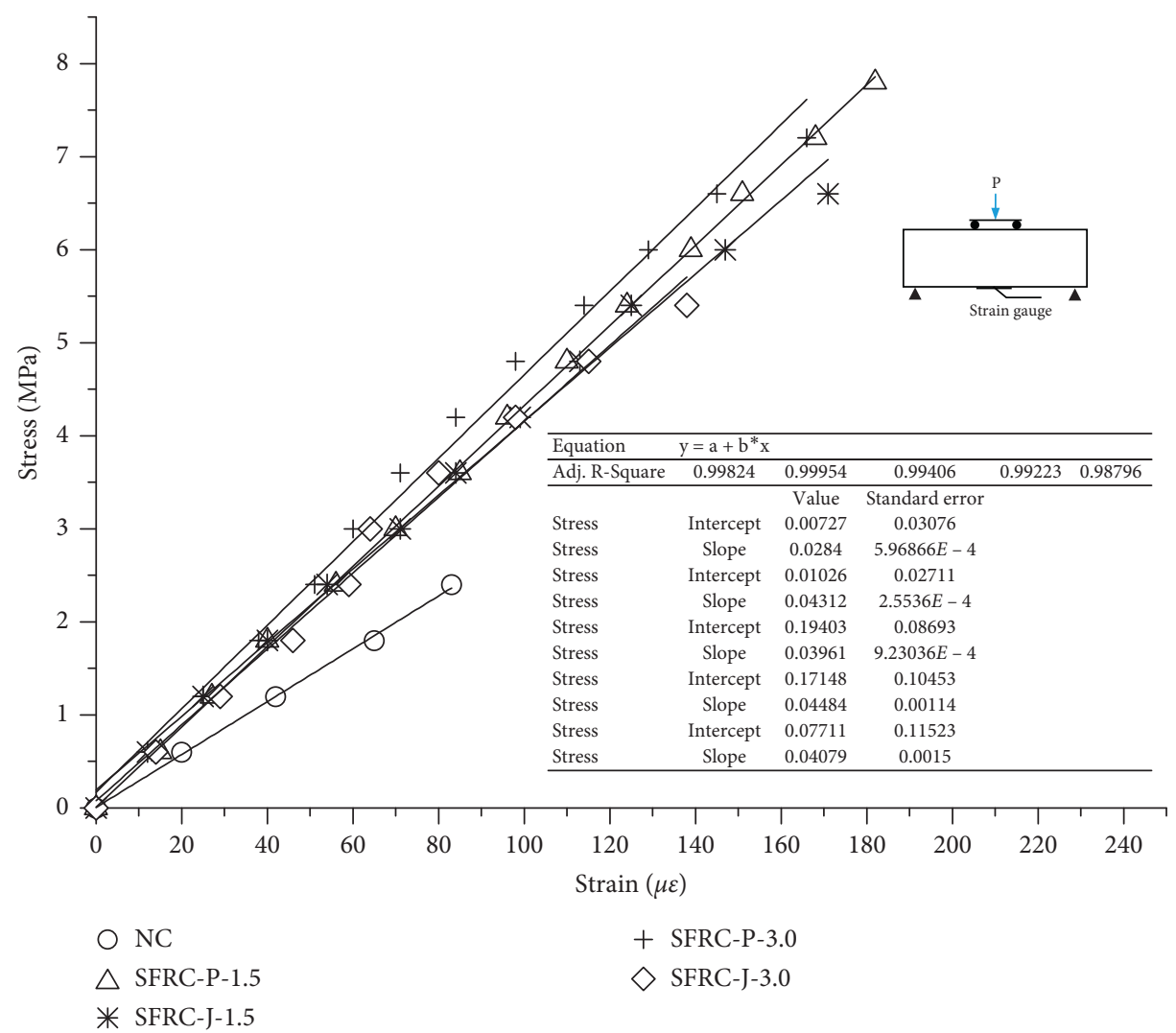

FIGURE 8: Plot of stress-strain curves.

The three-point bending flexural test was employed to evaluate the bending toughness of MSFRC prism specimens with size $400 \mathrm{~mm} \times 100 \mathrm{~mm} \times 100 \mathrm{~mm}$ as shown in Figure 9 . According to load-displacement curves at midspan of MSFRC specimens, the flexural toughness ratio $\left(R_{e}\right)$ was got by (3) suggested in Chinese standard CECS13:2009. Figure 9 shows that when the volume fraction of the microsteel fiber reaches $3.0 \%$, the load-deflection curves were characterized with a deflection hardening characteristic, which was nondistinctive:

$$
R_{e}=\frac{\Omega_{k}}{P_{\mathrm{cr}} f_{k}},
$$

where $f_{k}=L / 150$ ( $\mathrm{L}$ is the clear span of tested specimens), $\mathrm{mm} ; P_{\mathrm{cr}}$ is the first cracking load of MSFRC, N; $\Omega_{k}$ is the area under the load-displacement curve with a midspan deflection of $L / 150, \mathrm{Nmm}$.
3.4. Test Results. The hardened properties of the MSFRC mixes, including the compressive strength, the flexural strength, the elastic modulus, and the flexural toughness ratio, are listed in Table 6. $\bar{f}_{c c}$ and $\bar{f}_{c c}^{\prime}$ are the average value of the compressive strength and the residual compressive strength of concrete cube, respectively, while $\bar{f}_{\mathrm{cp}}$ and $\bar{f}_{\mathrm{cp}}^{\prime}$ are of concrete prism. $\bar{f}_{\mathrm{ct}}$ is the average value of the bending strength. $\bar{E}_{c}$ and $\bar{E}_{t}$ are the average value of the modulus of elasticity under compression and bending, respectively. $R_{e}$ is the flexural toughness ratio of MSFRC.

3.4.1. Strength and Elastics Modulus of MSFRC in Total Section. Compared with the reference group of $\mathrm{NC}$ in $\mathrm{Ta}-$ ble 6 , with the addition of microsteel fiber content from $1.5 \%$ to $3.0 \%$, the cubic compressive strength of MSFRC is increased by $5.0 \%$ to $21.0 \%$, the prismatic compressive 


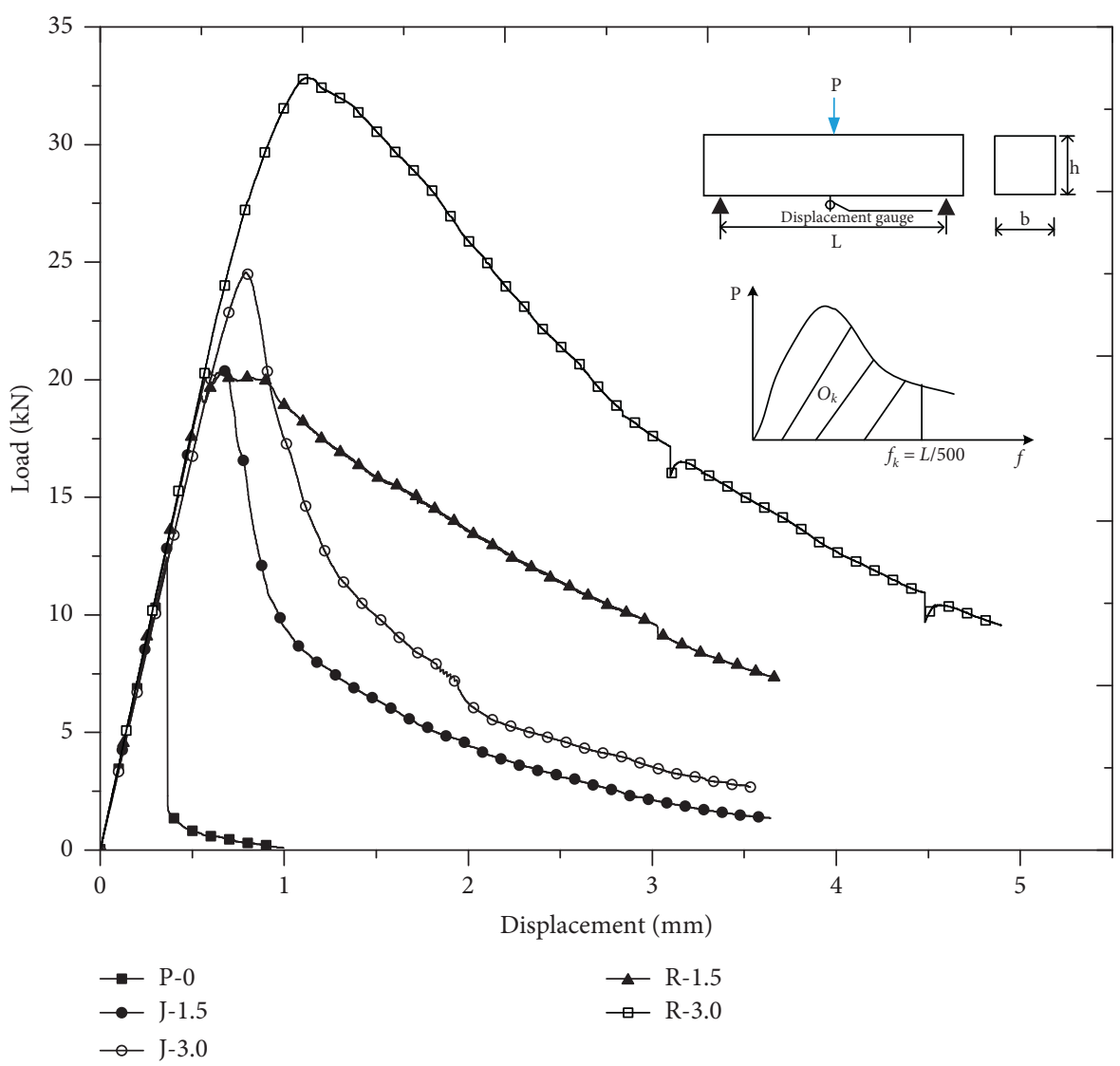

Figure 9: Plot of load-displacement curves.

TABle 6: Properties of hardened MSFRC.

\begin{tabular}{|c|c|c|c|c|c|c|c|c|c|}
\hline Group & $\bar{f}_{\mathrm{cc}}(\mathrm{MPa})$ & $\bar{f}_{c c}^{\prime}(\mathrm{MPa})$ & $\bar{f}_{\mathrm{cp}}(\mathrm{MPa})$ & $\bar{f}_{\mathrm{cp}}^{\prime}(\mathrm{MPa})$ & $\bar{E}_{c}(\mathrm{GPa})$ & $\bar{f}_{\mathrm{ct}}(\mathrm{MPa})$ & $\bar{E}_{t}(\mathrm{GPa})$ & $R_{e}$ & Note \\
\hline $\mathrm{NC}$ & 55.7 & - & 38.4 & - & 34.2 & 3.9 & 28.4 & - & NC in total section \\
\hline SFRC-P-1.5 & 58.5 & 45.7 & 46.6 & 35.9 & 35.6 & 7.6 & 43.8 & 0.57 & SFRC-P in total section \\
\hline SFRC-P-1.5-1/3 & & & - & & & 7.3 & - & & SFRC-P in partial section \\
\hline SFRC-P-3.0 & 67.4 & 55.0 & 48.0 & 35.4 & 35.8 & 10.0 & 44.8 & 0.70 & SFRC-P in total section \\
\hline SFRC-P-3.0-1/3 & & & - & & & 9.3 & - & & SFRC-P in partial section \\
\hline SFRC-J-1.5 & 63.5 & 41.5 & 48.0 & 33.9 & 35.5 & 7.6 & 39.6 & 0.32 & SFRC-J total section \\
\hline SFRC-J-1.5-1/3 & & & - & & & 7.1 & - & & SFRC-J in partial section \\
\hline SFRC-J-3.0 & 60.8 & 48.1 & 42.2 & 26.4 & 34.5 & 9.5 & 40.8 & 0.41 & SFRC-J in total section \\
\hline SFRC-J-3.0-1/3 & & & - & & & 8.5 & - & & SFRC-J in partial section \\
\hline
\end{tabular}

strength increased by $9.9 \%$ to $25.0 \%$, the compressive elastic modulus by $0.9 \%$ to $4.7 \%$, the bending strength improved by $94.9 \%$ to $156.4 \%$, and the flexural elastic modulus by $38.6 \%$ to $43.8 \%$. The ratio of $\bar{f}_{\mathrm{cp}}$ to $\bar{f}_{\mathrm{cc}}$ is $0.69 \sim 0.80$, and the ratio of $\bar{f}_{\text {ct }}$ to $\bar{f}_{\text {cc }}$ is $0.12 \sim 0.16$, which are improved in different extents compared with the ratio of the reference. The ratio of $\bar{f}_{\mathrm{cc}}^{\prime}$ to $\bar{f}_{\mathrm{cc}}$ is $0.65 \sim 0.82$, and the ratio of $\bar{f}_{\mathrm{cp}}^{\prime}$ to $\bar{f}_{\mathrm{cp}}$ is $0.63 \sim 0.77$, which indicate that MSFRC is characterized with good ductility. In the case of the same fiber content, the compressive strength and elastic modulus of MSFRC with Type I fiber are roughly equivalent to that with Type II, while the residual strength, bending strength, and flexural elastic modulus are slightly better. With the increase of fiber content, strength and modulus of MSFRC with Type I fiber increase more than that with Type II.
3.4.2. Bending Toughness of MSFRC in Total Section. According to Figure 9, for the reference normal concrete, when crack occurs, then the specimen suddenly collapses, which is characterized with obvious brittle failure. The first cracking load $P_{\text {cr }}$ determined from the load-deflection curve is equivalent to the ultimate load, while, as to MSFRC, the addition of microsteel fiber increases the first cracking load and ultimate load, and the descending portion of the loaddeflection curve is gentle, which show that MSFRC is characterized with good bearing capacity and deformability. Table 6 shows, in case of equivalent fiber volume content, the flexural toughness ratio $R_{e}$ of the MSFRC with Type I fiber is $69 \%$ to $77 \%$ higher than that with Type II; under the same fiber type, $R_{e}$ increases with fiber volume content, while Type I fiber has more significant effect on $R_{e}$ than Type II. 
3.4.3. Bending Strength of MSFRC in Partial Section. Table 6 shows that in case of the equivalent fiber volume content, the bending strength of partial MSFRC specimens involved with Type I fiber is slightly better than that with Type II; the bending strength of MSFRC in partial section is only $3.9 \%$ to $8.4 \%$ lower than that in full section, while fiber consumption is saved by two-thirds, which show a high costperformance ratio.

\section{Flexural Behavior of the RC Beam Partially Reinforced with MSFRC}

4.1. Design of the RC Beam Partially Reinforced with MSFRC. Materials study has found that MSFRC, involved with Type I fiber, has better strengthening and toughening effect than that with Type II, and MSFRC partially employed in tension zone is a cost-effective method. According to stress-strain field characteristics of beam structures, the pure bending state of the four-point bending RC beam can be simplified as a plane stress issue shown in Figure 10. The effect of a steel rebar in RC beam is to generate a pair of opposing concentrated forces shown in Figure 10(a), which act on the edge crack surface to prevent crack propagation [33-35], while, in the RC beam partially reinforced with MSFRC, due to crack-retarding and toughening effect of MSFRC, the edge crack becomes an internal eccentric crack shown in Figure 10(b), and the concentrated forces produced by the rebar provide crack closure forces partially.

But, in RC beams, due to large aspect ratio and strong orientation of steel rebar, the rebar's volume fraction is very small. Therefore, the rebar mainly plays the role of bridging discrete macroscopic cracks, while its bridging effect on microcracks is limited; thus, the crack resistance of RC beam mainly depends on concrete matrix itself, namely, the tensile strength of concrete matrix. In this paper, by arranging MSFRC in partial tension zone of RC beam shown as Figure 10(b), which is involved with Type I fiber, a composite beam partially reinforced with MSFRC is put forward. The quantity of microsteel fiber per cubic meter of concrete mix is inversely proportional to the square of the diameter; therefore, in the case of constant fiber volume content, compared with larger diameter steel fiber, there are more fibers per cubic meter of MSFRC, which can bridge a large number of microdefects or macrocracks in the material under load. Then, mechanical properties of the material are greatly improved; meanwhile, in the beam, the previous edge crack of an ordinary concrete beam shown in Figure 10(a) becomes a central crack in the RC beam partially reinforced with MSFRC shown in Figure 10(b). Other things being equal, the edge crack is easier to propagate than the center crack; thus, the crack resistance and serviceability of the RC beam partially reinforced with MSFRC will be improved greatly.

Therefore, the RC beam partially reinforced with MSFRC under four-point loading, involved without hangers, stirrups, and bent bars in the pure bending region, was designed as shown in Figure 11. HRB 335 deformed bars were employed as the longitudinal reinforcement and hanger, while HPB300 plain bars were used as stirrups and bent bars. In the region of the partially reinforced beam subjected to shear force and bending moment, the stirrup spacing is $50 \mathrm{~mm}$, and bent-bar spacing is $150 \mathrm{~mm}$. The yield strength, ultimate strength, elastic modulus, and percentage contraction of cross-sectional area at fracture of the longitudinal reinforcement are $392.5 \mathrm{MPa}, 505.0 \mathrm{MPa}, 210 \mathrm{GPa}$, and $26.5 \%$, respectively. The mix proportions and properties of the normal concrete and MSFRC are shown in Tables 5 and 6.

Two different kinds of sections were employed in the bending test, one of which identified as $R C$ beam is the normal concrete in full section, and the other is MSFRC in partial section involved with Type I microsteel fiber at the ratio of $1.5 \%$ volume fraction, identified as PSFRC beam. Based on the above conclusion and according to (2), the critical ratio of is about 0.3 , in which case the reinforcing effect of the beam partially reinforced by MSFRC is approximately equivalent to the beam with MSFRC in full section. Strain and deflection gauges were arranged according to Chinese standard for test method of concrete structures GB/T 50152-2012 shown in Figure 12.

\subsection{Bending Test Results of the RC Beam Partially Reinforced by MSFRC}

4.2.1. Load-Displacement Curves. Load-midspan displacement curves are shown in Figure 13, which take the load $P^{b}$ as ordinate and the midspan displacement $D^{b}$ as abscissa. Compared with the $R C$ beam, the first cracking load, yield load, and ultimate load of the PSFRC beam are increased by $119 \%, 21 \%$, and $12 \%$, respectively. The ratio of the first cracking load to the yield load is about 0.22 for the $R C$ beam but is 0.44 for the PSFRC beam. So, the partially reinforced beam is characterized with excellent crack resistance.

4.2.2. Crack Development and Failure Mode. The first crack that occurred in PSFRC beam was significantly later than that in $R C$ beam, and the height and width of the initial crack were much smaller under the same loading condition, which mean that the crack resistance of the RC beam partially reinforced with MSFRC was improved remarkably. After cracking, the height and width of cracks in PSFRC beam developed more slowly, and cracks reached the steady state later, where the number and height of cracks were kept stable. The height and width of the main crack varying with load are shown in Figures 14 and 15 , which take the load $P^{b}$ as ordinate and the main crack width $w$ and the height $h$ as abscissa. Results show that, under the control of same crack width, the bearing capacity of PSFRC beam is improved by about $50 \%$ or more than that of $R C$ beam, which contributes to the application of high-strength rebar in RC structures; for the RC beam, the steady state occurs at about $50 \%$ of the ultimate load and $70 \%$ for the PSFRC beam.

The typical crack distribution diagrams of the test beams are shown in Figure 16. Compared with the pure bending region of the $R C$ beam, the number of cracks in the PSFRC beam increases by $100 \%$; thus, the crack spacing is much smaller; meanwhile, some microcracks with small height occur during the loading, which mean that the stress 

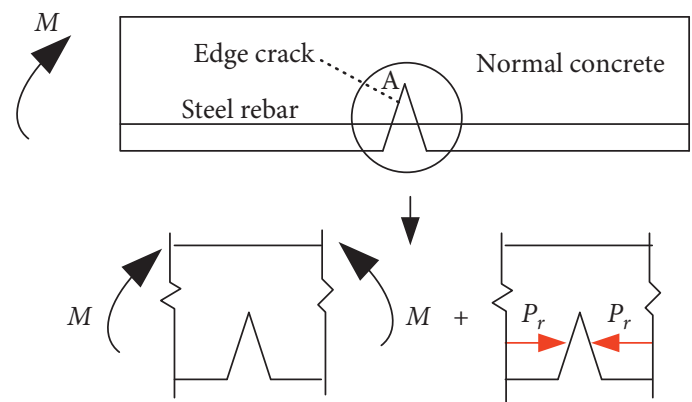

(a)
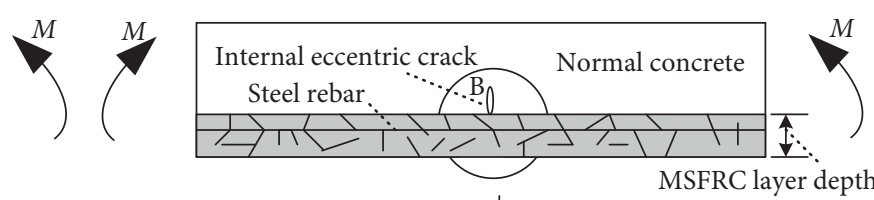

MSFRC layer depth

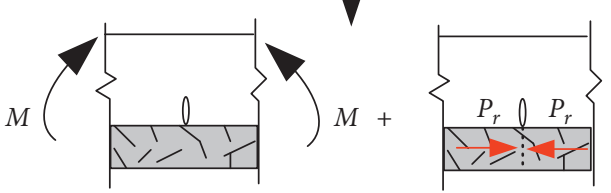

(b)

FIGURE 10: Crack-retarding and strengthening mechanism of the RC beam partially reinforced by MSFRC.
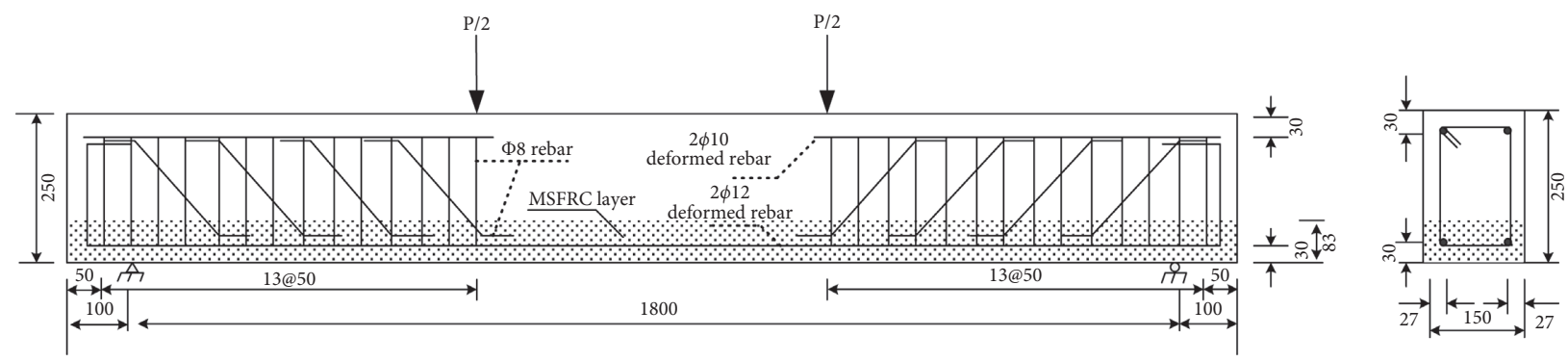

FIGURE 11: The RC beam partially reinforced by MSFRC.

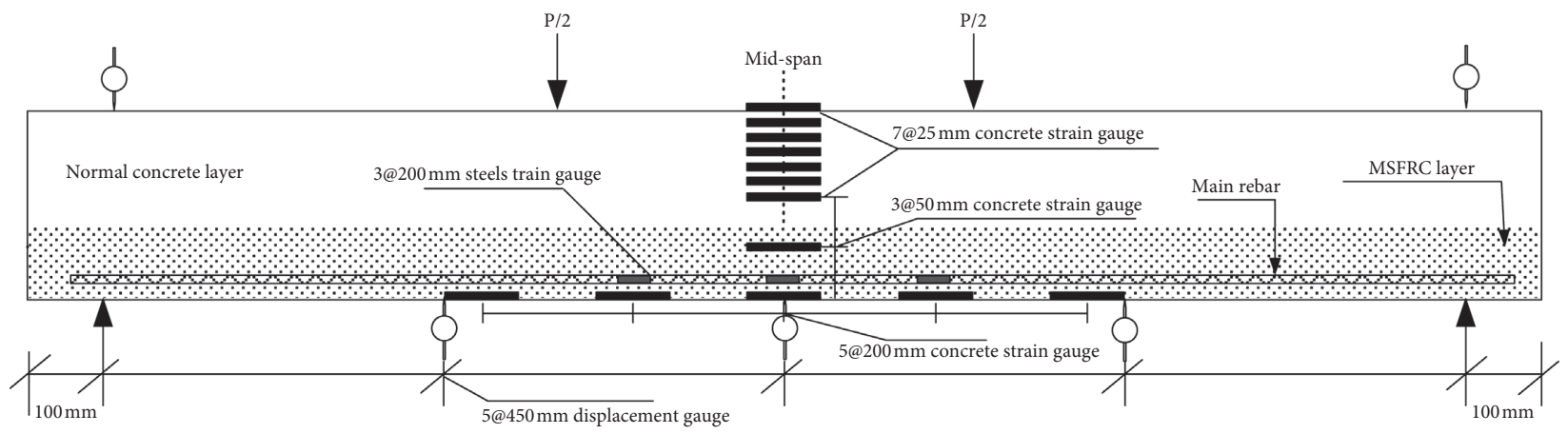

FIGURE 12: Arrangement of gauges for the RC beam partially reinforced by MSFRC.

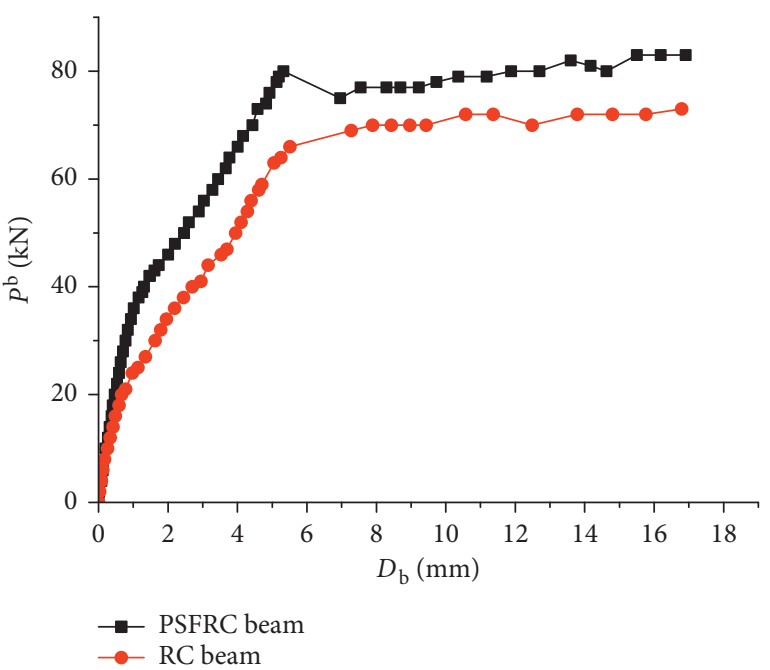

Figure 13: Lot of load versus displacement. 


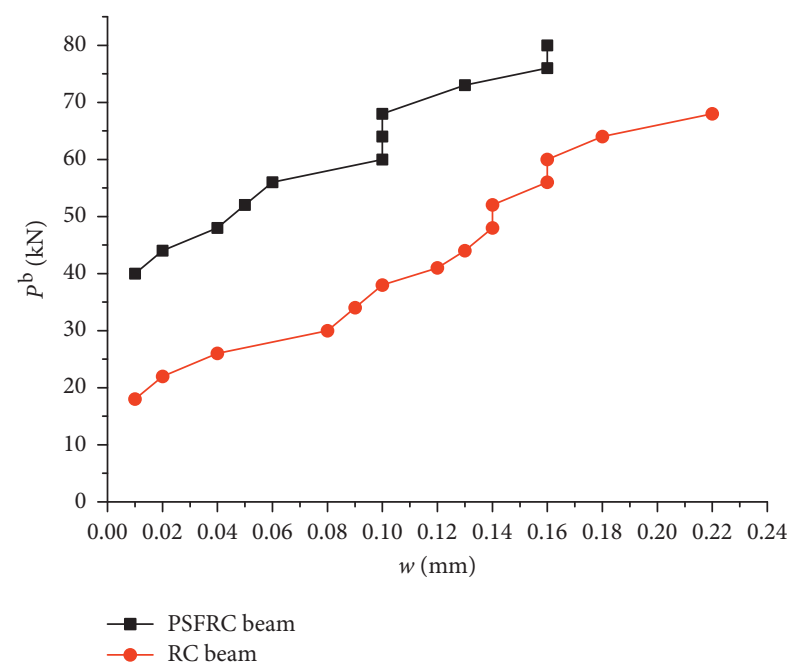

Figure 14: Plot of the main crack width versus load.

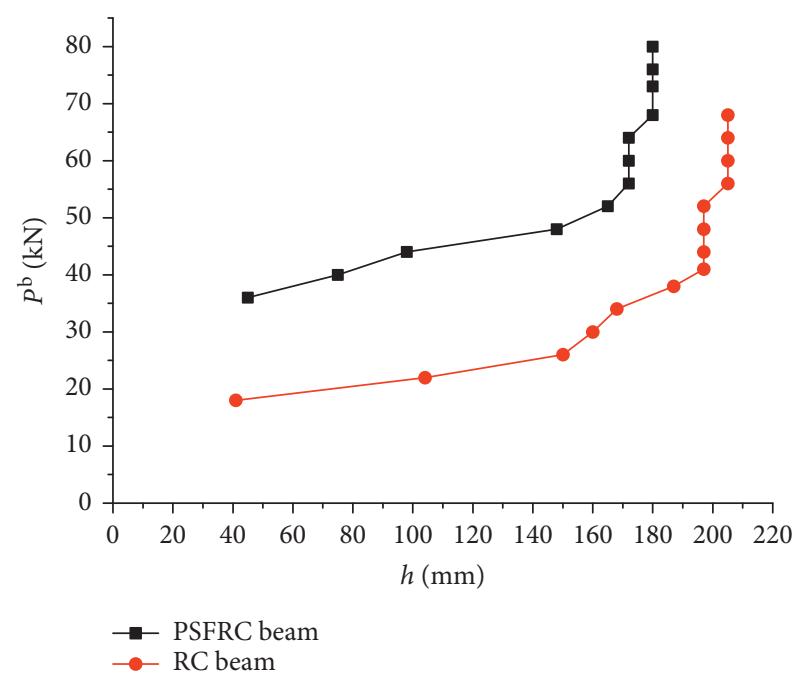

Figure 15: Plot of the main crack depth versus load.

distribution of steel bars is more uniform, and the bearing capacity of the PSFRC beam has been improved. In the bending-shear region, the number of cracks in the PSFRC beam is less than that of RC beam, so the RC beam partially reinforced with MSFRC can also improve the shear resistance. The bending failure model of the PSFRC beam is a typical ductile failure as shown in Figure 13.

\subsection{Bearing Capacity Calculation}

4.3.1. Cracking Load. According to the cracking load calculation diagram of normal section of the RC beam partially reinforced by MSFRC as shown in Figure 5, $\sigma_{\text {tu }}$ in (2) should be determined by the tensile stress-strain relationship curve of MSFRC or is 0.5 to 0.6 times the bending strength of the material, which varies with the fiber content [36]. The cracking moment $M_{\mathrm{cr}}$ is related to the influence coefficient of plastic section modulus $\gamma_{m}$, the standard tensile strength of concrete matrix $f_{\mathrm{tk}}$, and elastic section modulus $w_{0}$, which is listed as (4). According to Code for Design of Concrete Structures GB50010, for C40 concrete, $f_{t k}$ is $2.39 \mathrm{MPa}$ and $w_{0}$ is calculated by the principle of the equivalent elastic modulus. Equation (2) is employed to calculate $M_{\mathrm{cr}}$ and then obtain $\gamma_{m}$ according to the following:

$$
\gamma_{m}=\frac{M_{\mathrm{cr}}}{f_{\mathrm{tk}} w_{0}} .
$$

Assuming that $\gamma_{m}$ is the function of the reinforcement ratio $\rho$ and the fiber volume content $V_{f}$, the linear fitting method is used to obtain the calculation formula of cracking moment $M_{\mathrm{cr}}$, which is shown in the following:

$$
\left\{\begin{array}{l}
\gamma_{m}=1.132+4.5 V_{f}+k(\rho), \\
M_{c r}=\gamma_{m} f_{t k} w_{0},
\end{array}\right.
$$

where the influence factor of reinforcement ratio $k(\rho)$ reflects the influence of $\rho$ on $\gamma_{m}$.

In the test of the RC beam partially reinforced with MSFRC, the reinforcement ratio is constant; that is, the variable of reinforcement ratio is not involved in (5). Therefore, $k(\rho)$ is specified to be zero and needs to be explored in the next research.

After the cracking moment $M_{\text {cr }}$ is calculated according to (5), then the calculated cracking load $P_{\mathrm{cr}, j}^{b}$ of the beam under four-point loading can be obtained.

4.3.2. Ultimate Load. According to Code for Design of Concrete Structures GB50010 and Technical Specification for Fiber Reinforced Concrete Structures CECS38:2004, the calculation diagram of the ultimate moment of normal section of the RC beam partially reinforced with MSFRC $M_{u}$ is shown as Figure 17; then the calculation formula of ultimate moment $M_{u}$ is obtained as follows

$$
\left\{\begin{array}{l}
f_{c} b x=f_{y} A_{s}+f_{f t u} b x_{t}, \\
M_{u}=f_{c} b x\left(h_{0}-\frac{x}{2}\right)-f_{f t u} b x_{t}\left(\frac{x_{t}}{2}-a\right),
\end{array}\right.
$$

where $f_{c}$ is the compressive strength of concrete in compression zone, $f_{y}$ is the standard tensile strength of steel rebar, $x$ is the compression zone height, $x_{t}$ is the height of equivalent rectangular stress block of MSFRC in the tension zone, $f_{\mathrm{ftu}}$ is the tensile strength of the equivalent rectangular stress block, $h_{0}$ is the effective section height of the composite beam, and $a$ is the concrete cover depth. $f_{\mathrm{ftu}}$ is calculated according to the following:

$$
\left\{\begin{array}{l}
f_{f t u}=f_{t k} \beta_{t u} \eta_{f}, \\
\eta_{f}=V_{f} \lambda,
\end{array}\right.
$$

where $f_{\text {tk }}$ is the standard tensile strength of concrete matrix in RC beam partially reinforced with MSFRC, $\beta_{\text {tu }}$ is the influence coefficient of steel fiber on tensile behavior of MSFRC in the tensile zone of the partially reinforced beam, $\eta_{f}$ is the characteristic value of steel fiber in the partially reinforced beam, $V_{f}$ is the fiber volume fraction in MSFRC, 

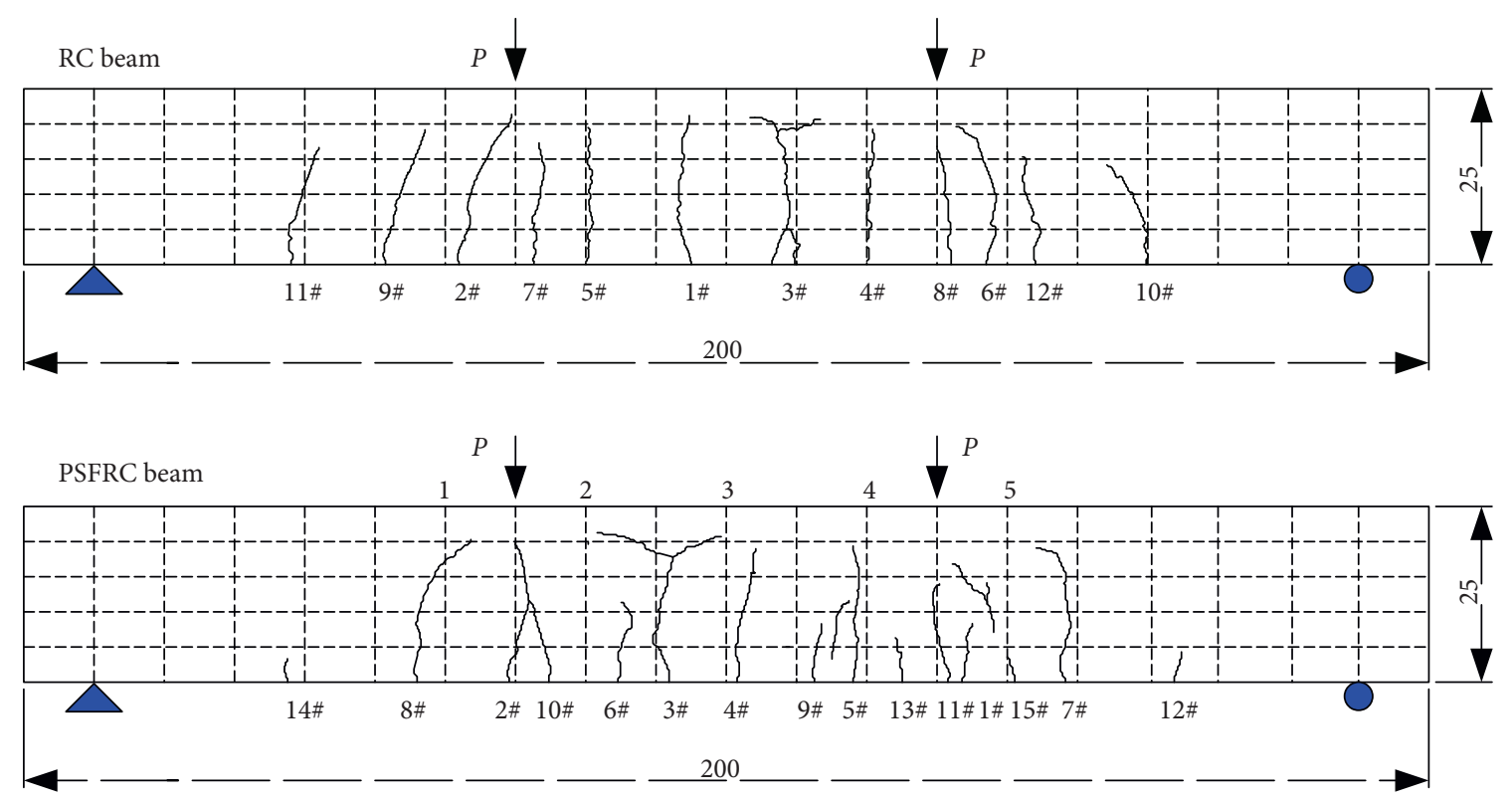

FIgURE 16: Typical crack distribution diagrams.

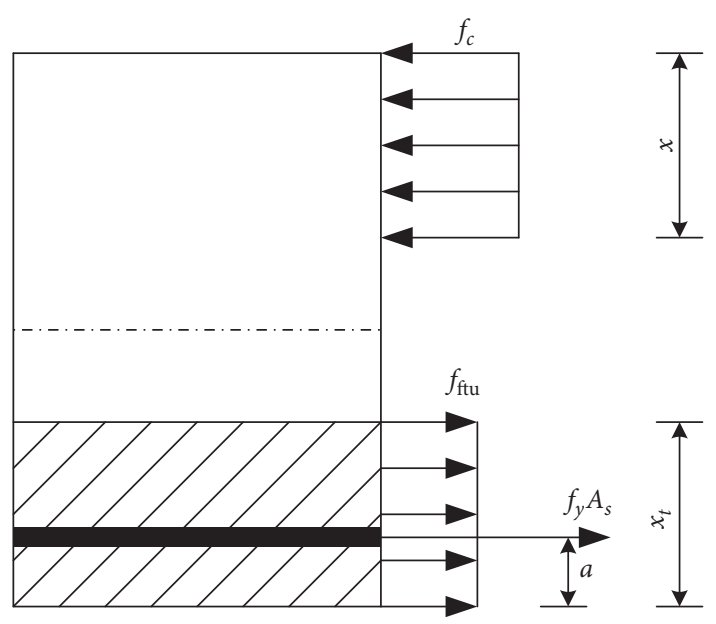

Figure 17: Ultimate moment calculation diagram of normal section.

TABLE 7: Calculated and experimental results of the cracking load and ultimate load.

\begin{tabular}{lcccc}
\hline Group & $P_{\mathrm{cr}, j}^{b}(\mathrm{kN})$ & $P_{\mathrm{cr}, t}^{b}(\mathrm{kN})$ & $P_{u, j}^{b}(\mathrm{kN})$ & $P_{u, t}^{b}(\mathrm{kN})$ \\
\hline RC beam & 14.4 & 16.8 & 61.2 & 73.8 \\
PSFRC beam & 32.5 & 36.8 & 75.0 & 83.0 \\
\hline
\end{tabular}

and $\lambda$ is the aspect ratio of steel fiber. In (7), $f_{t k}$ is $2.39 \mathrm{MPa}$ according to GB50010, and $\beta_{\text {tu }}$ is 1.3 for bending member according to CESS 38:2004.

4.3.3. Comparative Analysis of the Calculated and Experimental Results. The calculation of the cracking load and ultimate load of the test beam and the experimental results are shown in Table 7. In Table 7, $P_{\mathrm{cr}, j}^{b}$ and $P_{\mathrm{cr}, t}^{b}$, respectively, represent the calculated and experimental results of the cracking load, and $P_{u, j}^{b}$ and $P_{\mathrm{cr}, t}^{b}$ are of the ultimate load, which are in good agreement.

\section{Conclusion}

Through the experimental study on microsteel fiber reinforced concrete (MSFRC) and the RC beam partially reinforced with MSFRC, the following conclusions can be drawn:

(1) Compared with the reference group of the normal concrete, the compressive strength of the cubic and prismatic specimen for MSFRC is increased by $5.0 \%$ to $21.0 \%$ and $9.9 \%$ to $25.0 \%$, respectively, the bending strength is increased by $94.9 \%$ to $156.4 \%$, the compressive elastic modulus is increased by $0.9 \%$ to $4.7 . \%$, and the bending modulus is increased by $8.6 \%$ to $43.8 \%$, which indicate that the bending properties of MSFRC are significantly improved; the ratio of prismatic compressive strength and the bending strength of MSFRC to the cubic compressive strength is 0.69 to 0.80 and 0.12 to 0.16 , respectively, which are improved in varying degrees. Under the same conditions, the strength and modulus of MSFRC involved with Type I microsteel fiber are generally better than that with Type II, especially for bending properties.

(2) The residual compressive strength of the cubic and prismatic specimen for MSFRC is $65.3 \%$ to $81.6 \%$ and $62.6 \%$ to $77.0 \%$ of their primary loading strength, respectively, which are characterized with good ductility. In the same case, the residual strength of MSFRC involved with Type I micro steel fiber is also superior to that with Type II.

(3) Compared with the reference group of the normal concrete, the bending toughness of MSFRC is greatly enhanced. In the identical conditions, the bending 
toughness of MSFRC with Type I microsteel fiber has increased by $69 \%$ to $77 \%$ compared to Type II.

(4) The bending strength of the specimen partially reinforced with MSFRC is only $3.9 \%$ to $8.4 \%$ lower than that with MSFRC in the full section, but the steel fiber consumption is saved by two-thirds, which is costeffective. In the identical circumstances, the bending strength of concrete partially reinforced with MSFRC involved with $s$ Type II is superior to that with Type II.

(5) The critical depth of MSFRC layer in the RC beam partially reinforced with MSFRC is about 0.3 times the beam height, the crack-retarding, and strengthening effect of which is equivalent to the beam with MSFRC in full section. In the gradient design, the MSFRC layer and the normal concrete layer are simultaneously cracked, the roles of which can be fully utilized. Compared with the normal RC beam, the cracking load and the ultimate load of the partially reinforced beam were increased by $119 \%$ and $21 \%$, respectively; the crack width and height were developed more slowly, and cracks reached the steady state later. And when cracks tended to be steady, the number of cracks in the partially reinforced beam is more than that in the RC beam; thus, the crack spacing is much smaller, and meanwhile the number of cracks in the bending-shear region is less than that of RC beam, which revealed the superior crack-control capacity and bending resistance of the partially reinforced beam. The calculation of bearing capacity is also in good agreement with the experimental results.

\section{Data Availability}

The data used to support the findings of this study are available from the corresponding author upon request.

\section{Conflicts of Interest}

The authors declare that they have no conflicts of interest.

\section{Acknowledgments}

The authors sincerely thank the Natural Science Foundation of Chongqing (no. cstc2019jcyj-msxmX0744), China, Scientific and Technological Research Program of Chongqing Municipal Education Commission (no. KJ1500512), Foundation of State Key Laboratory of Mountain Bridge and Tunnel Engineering (CQSLBF-2015-12), and Science Foundation of Chongqing Jiaotong University (20JDKJCB006) for financial support.

\section{References}

[1] Q. Luo, D. Liu, P. Qiao, Q. L. Feng, and L. Z. Sun, "Microstructural damage characterization of concrete under freezethaw action," International Journal of Damage Mechanics, vol. 27, no. 10, pp. 1551-1568, 2018.
[2] S. Ghanbarpour, H. Mazaheripour, S. H. Mirmoradi, and A. Barari, "The effect of type and volume fraction (VF) of steel fiber on the mechanical properties of self-compacting concrete," Journal of Engineering, Design and Technology, vol. 8, no. 3, pp. 247-256, 2010.

[3] J. J. Yang and J. X. Liu, "Studies on mechanical property of high fluidity steel fibre reinforced ultra-high strength concrete," Journal of Building Materials, vol. 13, no. 1, pp. 1-6, 2010.

[4] Y. M. Kang and C. W. Liu, "A study of the damage and deformation characteristics of steel fibre reinforced concrete with different steel fibre sizes," China Civil Engineering Journal, vol. 43, no. 4, pp. 119-124, 2010.

[5] K. Habel, M. Viviani, E. Denarié, and E. Brühwiler, "Development of the mechanical properties of an ultra-high performance fiber reinforced concrete (UHPFRC)," Cement and Concrete Research, vol. 36, no. 7, pp. 1362-1370, 2006.

[6] N. V. Tue, S. Henze, M. Küchler, G. Schenck, and K. Wille, "Ein optoanalytisches Verfahren zur Bestimmung der Faserverteilung und -orientierung in stahlfaserverstärktem UHFB," Beton-und Stahlbetonbau, vol. 102, no. 10, pp. 674-680, 2007.

[7] C. Wang and O. M. Liza, "Preparation and mechanical properties of super high-strength steel micro-fibre toughened concrete," China Civil Engineering Journal, vol. 42, no. 6, pp. 1-7, 2009.

[8] Z. D. Rong, W. Sun, Y. S. Zhang, and W. She, "Anti-penetration behavior of ultra-high performance steel fibber reinforced concrete and its numerical simulation," Journal of the Chinese Ceramic Society, vol. 38, no. 9, pp. 1723-1730, 2010.

[9] A. K. F. Cheung and C. K. Y. Leung, "Effective joining of precast concrete slabs with self-compacting HSFRCC," Journal of Advanced Concrete Technology, vol. 9, no. 1, pp. 41-49, 2011.

[10] Q. Luo, D. Liu, P. Qiao, Z. Zhou, Y. Zhao, and L. Sun, "MicroCT-based micromechanics and numerical homogenization for effective elastic property of ultra-high performance concrete," International Journal of Damage Mechanics, vol. 29, no. 1, pp. 45-66, 2020.

[11] Z. H. Wang, H. X. Zhou, G. Cui, and J. Lv, "Experiments study of different steel fibre on the low strength grade of C30 pump concrete," Concrete, vol. 7, pp. 95-98, 2012.

[12] L. Zhang and Y. Peng, "The effect of shear ultra-short superfine steel fibre in reinforcing the concrete performance," Value Engineering, vol. 1, pp. 66-68, 2013.

[13] R. N. Swamy and K. A. Al-Noori, "Flexure behavior of fibre concrete with conventional steel reinforcement," in Proceedings of the Fiber Reinforced Cement and Concrete, RILEM Symposium, pp. 187-196, London, UK, September 1975.

[14] R. Sri Ravindrarajah and C. T. Tam, "Flexural strength of steel fiber reinforced concrete beams," The International Journal of Cement Composites and Lightweight Concrete, vol. 6, no. 4, pp. 273-278, 1978.

[15] C. Yi and S. Z. Shen, "Study on flexural properties of partially high-percentage fiber reinforced concrete component," Industrial Building, vol. 28, no. 8, pp. 1-5, 1998.

[16] Y. Cheng and S. Shen, "Calculation and analysis of main influent factors of cracked section of beam reinforced by partially high percentage fiber and steel bars," Industrial Construction, vol. 30, no. 7, pp. 44-46, 2000.

[17] J. Zhao, H. T. Zhu, and D. Y. Gao, "Steel fiber reinforced concrete beam cross-section crack resistance calculation method of," Industrial Construction, vol. 31, no. 3, pp. 31-34, 2001. 
[18] J. J. Yang and Y. L. Dong, "Effect of fibre gradient distribution on the concrete strength," Henan Science, vol. 20, no. 6, pp. 645-648, 2002.

[19] F. Qin, Z. Zhang, Z. Yin, J. Di, L. Xu, and X. Xu, "Use of high strength, high ductility engineered cementitious composites (ECC) to enhance the flexural performance of reinforced concrete beam," Journal of Building Engineering, vol. 32, Article ID 101746, 2021.

[20] Q. H. Li and S. L. Xu, "Experimental study on high toughness properties of composite materials and crack control functionally graded beam bends," Science in China Series E: Technological Sciences, vol. 39, no. 8, pp. 1391-1406, 2009.

[21] Z. Zhang, F. Yang, J.-C. Liu, and S. Wang, "Eco-friendly high strength, high ductility engineered cementitious composites (ECC) with substitution of fly ash by rice husk ash," Cement and Concrete Research, vol. 137, Article ID 106200, 2020.

[22] Z. Zhang, A. Yuvaraj, J. Di, and S. Qian, "Matrix design of light weight, high strength, high ductility ECC," Construction and Building Materials, vol. 210, pp. 188-197, 2019.

[23] Z. Zhang, J.-C. Liu, X. Xu, and L. Yuan, "Effect of sub-elevated temperature on mechanical properties of ECC with different fly ash contents," Construction and Building Materials, vol. 262, Article ID 120096, 2020.

[24] Z. Zhang, Q. Zhang, and V. C. Li, "Multiple-scale investigations on self-healing induced mechanical property recovery of ECC," Cement and Concrete Composites, vol. 103, pp. 293-302, 2019.

[25] Z. Zhang, J. Hu, and H. Ma, "Feasibility study of ECC with self-healing capacity applied on the long-span steel bridge deck overlay," International Journal of Pavement Engineering, vol. 20, no. 8, pp. 884-893, 2019.

[26] H. Ma and Z. Zhang, "Paving an engineered cementitious composite (ECC) overlay on concrete airfield pavement for reflective cracking resistance," Construction and Building Materials, vol. 252, Article ID 119048, 2020.

[27] Z. Zhang, F. Qin, H. Ma, and L. Xu, "Tailoring an impact resistant engineered cementitious composite (ECC) by incorporation of crumb rubber," Construction and Building Materials, vol. 262, Article ID 120116, 2020.

[28] W.-J. Ge, A. F. Ashour, X. Ji, C. Chen, and D.-F. Cao, "Flexural behavior of ECC-concrete composite beams reinforced with steel bars," Construction and Building Materials, vol. 159, pp. 175-188, 2018.

[29] H. Cai, S. Cheng, D. Gao, S. M. Neaz, and C. Li, "Flexural behavior of partially fiber-reinforced high-strength concrete beams reinforced with FRP bars," Construction and Building Materials, vol. 161, pp. 587-597, 2018.

[30] Z. J. Yi, Q. G. Yang, Z. W. Li et al., "Use of fracture mechanics concept to interpret crack resistance behavior of fibre reinforced concrete," Journal of Chongqing Jiaotong University, vol. 23, no. 6, pp. 43-45, 2004.

[31] Y. Dong, C. Su, and P. Qiao, "An improved mesoscale damage model for quasi-brittle fracture analysis of concrete with ordinary state-based peridynamics," Theoretical and Applied Fracture Mechanics, Article ID 102829, 2020.

[32] Y. Dong, C. Su, P. Qiao, and L. Sun, "Microstructural damage evolution and its effect on fracture behavior of concrete subjected to freeze-thaw cycles," International Journal of Damage Mechanics, vol. 27, no. 8, pp. 1272-1288, 2018.

[33] X. B. He, X. B. Guo, Y. Li et al., "Strengthening mechanism of concrete beam strengthened with externally bonded interply hybrid GFRP/CFRP," Journal of Huazhong University of Science and Technology, vol. 42, no. 1, pp. 78-83, 2014.
[34] X. B. He, F. Huang, and C. Y. Zhang, "Mechanism and experimental verification of degradation of RC beams induced by concrete/rebar bonding failure," KEM, vol. 452/453, pp. 877-880, 2011.

[35] S. S. Lu and W. Z. Zheng, "Calculation method for crosssectional crack resistance of reactive powder concrete beams reinforced with GFRP bars," Journal of Harbin Institute of Technology, vol. 4, no. 42, pp. 536-540, 2010.

[36] X. F. Zhang and S. L. Xu, "Improvement of the flexural and cracking behavior of RC beams using ultra-high toughness cementitious composites (I): theoretical analysis," China Civil Engineering Journal, vol. 41, no. 12, pp. 48-54, 2008. 